\title{
Modernización, Estado y estructura social según Antonio Gramsci
}

\section{Modernization, State and social structure according to Antonio Gramsci}

DOI: https://doi.org/10.29166/tyc.v1i22.2474

\begin{abstract}
Martha Rodríguez Albán
Licenciada en Ciencias de la Educación, con mención en Lengua y Literatura (Universidad Técnica Particular de Loja); Magíster en Estudios de la Cultura (UASB-Ecuador), Magíster en Ciencias Sociales (FLACSO-Ecuador); PhD en Literatura Latinoamericana (UASB-Ecuador). Ha publicado: Narradores ecuatorianos de 1950: Poéticas para la lectura de modernidades periféricas (2009) y Cultura y política en Ecuador: estudio sobre la creación de la Casa de la Cultura (2015). Mantiene inéditos los trabajos "Crítica literaria y sociedad. Ecuador, 1930-2000", y su tesis doctoral "Pasillo ecuatoriano, radio e industrias culturales, 1920-1965: disputas por el mercado de la música y el poder simbólico en el campo cultural". Docente de Teorías de la Cultura en la Facultad de Comunicación Social de la Universidad Central del Ecuador.
\end{abstract}

Correo: m1rodriguez@yahoo.com

\section{Resumen}

En este trabajo la autora revisa algunas reflexiones de Antonio Gramsci acerca del Estado, la estructura social y la modernización. El pensador italiano desembarazó a la "filosofía de la praxis" de los acartonamientos reduccionistas y economicistas que promovió la política de la Komintern, sobre todo, por su mirada a las estructuras sociales y a los procesos de construcción de hegemonía y contrahegemonía en las relaciones sociales. Respecto a la construcción de la hegemonía revisa el papel de dos instituciones -la escuela y el periodismo- mediante las cuales los intelectuales cumplen las funciones de adecuación y consenso. Además, al pensar al Estado y la sociedad civil -orgánicamente relacionados- convoca a otros conceptos como: bloque histórico y reforma moral e intelectual.

Palabras clave: Antonio Gramsci, Estado, modernización, hegemonía, sociedad civil.

\section{Abstract}

In this paper the author reviews some reflections of Antonio Gramsci about the State, the social structure, and the modernization. The Italian thinker freed the "philosophy of praxis" from the reductionist and economicist stiffening that the politics of the Komitern promoted, mainly, by his look at social structures and the processes of construction of hegemony and counter-hegemony in social relations. Regarding the construction of hegemony, he reviews the role of two institutions - school and journalism - through which intellectuals fulfill the functions of adequacy and consensus. In addition, when thinking about the State and civil society -organically related- it summons other concepts of its own such as: historical bloc and moral and intellectual reform.

Keywords:Antonio Gramsci, State, modernization, hegemony, civil society. 
El pensamiento del filósofo, político y crítico literario y cultural Antonio Gramsci (Ales, 1891 - Roma, 1937) ha ganado resonancia en el devenir socio-político de Occidente desde la segunda mitad del siglo XX. Sobre todo en el tercio final del mismo, cuando se sucedieron violentos cambios en los ámbitos económico (nueva crisis del capitalismo e intentos por recuperar el modelo liberal; preeminencia del capital financiero; cambios en el mapa económico mundial), político (luego de un período de auge revolucionario en Latinoamérica y en África, la crisis de la ex URSS y del mapa socialista con la caída del muro de Berlín), y social (reversión de las políticas keynesianas de la segunda posguerra; ahondamiento de la distancia entre las clases sociales y entre los países del norte y del sur).

Estos cambios reclamaban nuevos paradigmas de interpretación, así como nuevas praxis. Desde los años en que fueron escritos, los paradigmas gramscianos lo que hicieron fue volver más nítida la lectura de sus fuentes: Maquiavelo, Hegel y, sobre todo, el materialismo dialéctico de Marx. En efecto, con sus obras anteriores a 1927y con Cuadernos de la cárcel, este dirigente del movimiento obrero y fundador del Partido Comunista italiano combatió algunos presupuestos y conceptos de la teoría liberal; al mismo tiempo, desembarazó a la filosofía de la praxis de los acartonamientos reduccionistas y economicistas que promovió la política de la Komintern. Con sus reflexiones proporcionó, a partir de postulados marxistas, renovadas herramientas conceptuales para la interpretación de las realidades que conoció el autor y de las generaciones posteriores.

Gramsci acuñó tales conceptos desde su gnoseología - con fuente en el materialismo histórico- centrándose en una reflexión vital sobre el poder. Se trata de conceptos dinámicos, que buscan captar flujos, cambios, procesos históricos, relaciones orgánicas: no cosas estancas ni estados coagulados de la sociedad o las instituciones. De sus aportes conceptuales, en este ensayo revisaré tres: sus reflexiones sobre el Estado, la estructura social y la modernización. Resultan de particular interés para leer la historia de países con "modernidades periféricas" y, en particular, procesos de formación nacional-populares y de modernización.

Antes de empezar, hay que indicar que es difícil hablar de manera aislada de cada concepto, pues ellos se encuentran relacionados por vínculos de presuposición mutua. Existe una relación orgánica entre ellos. Incluso, es necesario recurrir a otros más -como hegemonía, intelectuales, bloque histórico- para poder comprender qué son el Estado y la sociedad civil, cómo el poder se distribuye en esas instancias, y qué rol juegan las instituciones que trabajan para la consolidación del dominio de una clase social en el control de la institución política. Por otro lado, ya se verá que el autor emplea estos conceptos con un sentido más amplio y que es necesario diferenciarlos del uso coloquial y del empleo contemporáneo de los mismos.

Comenzaré con el concepto de sociedad. Para Gramsci, ésta constituye un sistema, un todo cuyos elementos no pueden leerse por separado. Es esta complejidad misma de lo social lo que vuelve difícil su aprehensión a partir de epistemologías que tienden a considerar por separado las partes de un todo. Esta concepción de la realidad implica la presuposición mutua de los elementos económicos, políticos y culturales de cada formación particular, de producciones en esos ámbitos y de disputas entre clases. 
Aquí aparece el primer concepto del autor: "Para expresar está unidad dialéctica entre los momentos estructurales y superestructurales, Gramsci utilizó el concepto de "bloque histórico" (Acanda, 2007, p.10). Este concepto representa los equilibrios inestables de las luchas entre clases dominantes, cuyas relaciones son de lucha de poder para alcanzar y consolidar la hegemonía. Una clase dominante logra hegemonía cuando refuncionaliza las inconformidades y consigue integrar la actividad social contrahegemónica. Cada clase dominante realiza este proceso de estructuración de la producción material y espiritual -y de integración de la producción contrahegemónica- de una forma particular, que será su manera de organizar la hegemonía. Y el Estado defenderá los intereses de la clase, o clases dominantes, en esa formación particular.

Ahora bien, si se habla de lucha de clases, ¿cómo ve Gramsci ubicadas en la sociedad a las clases subalternas? Plantea que ellas:

por definición, no están unificadas y no pueden unificarse mientras no puedan devenir 'Estado': su historia, por lo tanto, está entrelazada con la de la sociedad civil, es una función 'disgregada' y discontinua de la historia de la sociedad civil y, por este trámite, de la historia de los Estados o grupos de Estados (Gramsci, 2008, p.35).

Esta pertenencia a la sociedad civil ofrece hálitos de esperanza -más allá del continuo saboteo de las iniciativas de los grupos subalternos por las clases en el poder, que juzga y lamenta Gramsci (2008, p.38)-, en la medida en que la praxis de las organizaciones populares abre ámbitos de participación, abona en la conquista de espacios de enunciación $y$, por ende, de reproducción- en el seno de dicha sociedad civil, más allá de que muchas veces pueda perderlos pronto y de que haya necesidad de recuperarlos.

Gramsci define a la sociedad civil como "la hegemonía política y cultural de un grupo social sobre la entera sociedad, como contenido ético del Estado" (Gramsci, 2007, pp. 290-291). E insiste en que no hay separación entre sociedad política y sociedad civil. Teniendo en cuenta esto, plantea:

\footnotetext{
Por ahora se pueden fijar dos grandes planos superestructurales, el que se puede llamar de la 'sociedad civil', que está formado por el conjunto de los organismos vulgarmente llamados 'privados' y el de la ‘sociedad política o estado' que corresponde a la función de 'hegemonía' que el grupo dominante ejerce en toda la sociedad y la del 'dominio directo' o de comando que se expresa en el estado y en el gobierno 'jurídico'. Estas funciones son precisamente organizativas y conectivas (Gramsci, 1975, p.17).
}

Gramsci reflexiona sobre los fenómenos de la sociedad desde la perspectiva de la producción y distribución de las relaciones de poder. Considera que éste es ubicuo y que las relaciones de poder o de fuerza son transversales. Por otro lado, poder y dominación guardan también una relación orgánica: a determinado patrón de acumulación de poder acompaña un específico patrón de dominación, aunque Gramsci no emplee estos términos para referirse a esas nociones. Sin embargo, es necesario referirse a ellas pues, como señala el filósofo cubano Jorge Luis Acanda (2007), no es posible entender la teoría gramsciana del poder fuera del marco de los planteamientos del filósofo y sociólogo alemán Max Weber (Erfurt, 1864 - Munich, 1920).

Algunos de los planteamientos weberianos son: que la racionalidad econó- 
mica es un proceso objetivo del capitalismo que se expande a todas las formas de vida social; que la clave del poder de la burguesía tiene que ver con dicha lógica racional económica: ella uniformiza o encuentra elementos en común en objetos y procesos que son radicalmente diferentes al condicionar el funcionamiento de todos ellos conforme a la lógica del capital, puesto que dicha lógica se expande y abarca y "coloniza" todos los ámbitos de la vida social. Esta lógica inmanente del capitalismo se desarrolla con más fuerza a medida que el desarrollo tecnológico avanza. La modernidad capitalista está marcada por la tecnología. Para Weber, el fundamento de la sociedad -y la clave de la dominación- es material. Para Gramsci también. La diferencia es que el italiano extiende la noción de poder más allá de lo económico: a lo social, lo ético/político, a lo cultural, que articula todos esos ámbitos, de manera orgánica.

Esta es una de las claves "para leer a Gramsci" y entender su concepto de sociedad civil en su imbricación con el Estado. Jorge Luis Acanda reseña que, para Marx, la noción de sociedad civil tiene un acento económico, pero que alude necesariamente a las interrelaciones sociales: “'Sociedad civil burguesa' (bürgerliche Gesellschaft) designa al modo de división y organización social del trabajo en condiciones de predominio del capital" (Acanda, 2007, p.24). Señala la insistencia de Marx en el carácter relacional de la sociedad civil: "abarca un complejo sistema de relaciones intersubjetivas. Es un concepto enfilado a designar un sector específico del tejido de relaciones sociales" (Ibid., p.25). Plantea que Marx buscaba "destacar el carácter enajenante no sólo de esa formación estatal, sino del Estado burgués y de todo Estado en general", a diferencia de Hegel. Realiza su crítica al Estado "como detentador del poder social [y por su] centralidad de la relación capital-trabajo en la construcción de las relaciones de poder" (Ibid.).

Gramsci da un paso más adelante en la clarificación de este concepto. Plantea que, por una parte, el Estado no debe confundirse con gobierno, pues esta confusión implica otra: la de sociedad civil con sociedad política. No son lo mismo, aunque estén imbricadas íntimamente, pues cada una representa funciones sociales distintas. Gramsci (1998) resalta que "en la noción general de Estado intervienen elementos que hay que reconducir a la noción de sociedad civil (en el sentido, pudiera decirse, de que Estado = sociedad política + sociedad civil, o sea, hegemonía acorazada con coacción)" (p.102). Tampoco la sociedad civil se limita a un conjunto de organizaciones educativas, económicas, civiles, etc. que ejercen coerción -noción desde el liberalismo-. Gramsci añade que estas organizaciones cumplen tal función, pero que son también responsables de la dirección moral y cultural de la sociedad. Para él, no es posible separar la sociedad política de la sociedad civil. Si se lo hace, es por razones metodológicas.

De su parte, el Estado es gobierno, pero además es institucionalidad pública, que ejerce coerción y desempeña funciones adicionales para alcanzar la dirección moral y cultural de la sociedad. De modo similar, la sociedad civil comprende un conjunto de procesos, instituciones y formas de actividad que producen civilidad en las personas. Civilidad es el conjunto de representaciones y valores de los individuos, socialmente establecido, a través del cual ellos modulan su relación con la realidad. 
Adicionalmente, no solo el Estado detenta el poder: en la sociedad civil también se encuentra éste, difusamente extendido: ella está atravesada por relaciones de poder. La diferencia entre sociedad civil y sociedad política es, entonces, metodológica y no orgánica; un ejemplo de ello es la escuela, que pertenece al Estado y a la sociedad civil. Para Weber, la sociedad es un sistema, pero no plantea que haya una relación orgánica.

La expansión del poder controlador del Estado se vuelve evidente, sobre todo desde la segunda mitad del siglo XIX. Junto a la expansión de la racionalidad del capitalismo, el Estado y sus instituciones abarcan y alcanzan, de manera manifiesta, otros ámbitos sociales que antes se consideraban separados de aquel (la familia, la escuela), y que aparentemente no son instituciones represivas. Con este concepto, Gramsci llega al centro de lo que buscaba comprender y explicar Weber: cómo la burguesía logró mantenerse en el poder. La clave es la hegemonía, que se apoya en su capacidad para producir valores, representaciones, deseos, etc., cuyas implicaciones tienen que ver con la percepción de la naturaleza de la economía.

La clave está en que el poder no solo implica coerción sino también consenso, y éste se obtiene a través del dominio moral y cultural: por eso el poder no solo se ejerce desde el Estado y por eso él se mantiene gracias a la labor de la "cadena de fortalezas y casamatas" que constituye la sociedad civil, modelada desde y para todas las instituciones y las estructuras de relaciones sociales que la conforman.

Cuando Gramsci habla de Estado ampliado, lo describe, en efecto, como la conjunción de sociedad civil con sociedad política. Al ser dinámica la sociedad civil, se entiende que los Estados implican también procesos dinámicos. Unidas orgánicamente la sociedad política y la sociedad civil, ésta se caracteriza por constituir un espacio mayor para la lucha de clases. "El Estado sólo era una trinchera avanzada, detrás de la cual existía una robusta cadena de fortalezas y casamatas" (Acanda, 2007, p.12). Esta "cadena de fortalezas y casamatas" es la sociedad civil; ella está regida por un específico modelo hegemónico de acumulación, que se ha consolidado como poder político a base de "la 'dirección intelectual y moral' de la sociedad, sobre la impregnación ideológica de todo el sistema social" (Ibid.).

En estas funciones de control y de hegemonía intelectual y moral desempeñan un rol fundamental los intelectuales. Su presencia permite visibilizar las maneras en las cuales el poder se extiende y existe difusamente en toda la sociedad, y la manera en que los intelectuales participan en los procesos de producción, no solo espiritual, sino material también.

La relación entre los intelectuales y el mundo de la producción no es una relación inmediata, como ocurre con los grupos sociales fundamentales, sino que es 'mediata' en grado diverso en todo el tejido social y en el complejo de la superestructura de la que los intelectuales son 'los funcionarios' (Gramsci, 1975, p.17).

Más adelante, lo expresa de manera más directa:

Los intelectuales son los 'empleados' del grupo dominante para el ejercicio de las funciones subalternas de la hegemonía social y del gobierno político, a saber: 1) del 'consenso' espontáneo que las grandes masas de la población dan a la dirección impuesta a la vida social por el grupo social dominante, consenso que históricamente nace del prestigio (y por tanto de la confianza) detentada 
por el grupo dominante, de su posición y de su función en el mundo de la producción; 2) del aparato de coerción estatal que asegura 'legalmente' la disciplina de aquellos grupos que no 'consienten' ni activa ni pasivamente, pero que está preparado por toda la sociedad en previsión de los momentos de crisis en el comando y en la dirección, casos en que el consenso espontáneo viene a menos (Gramsci, 1975, p.18).

Existen muchas instituciones a través de las cuales los intelectuales cumplen estas funciones de control, enseñanza y aprendizaje de la civilidad, de adecuación y consenso a la hegemonía de la clase dominante. Dos de ellas, a las que les dedica espacio en su reflexión, son la escuela y el periodismo. Para Gramsci, la escuela:

es el instrumento para formar los intelectuales de diverso grado. La complejidad de las funciones intelectuales en los diversos estados se puede medir objetivamente por la cantidad de escuelas especializadas y por su jerarquización: cuando más extensa es el 'área' escolar y cuanto más numerosos son los 'grados' 'verticales' de la escuela, tanto más complejo es el mundo cultural, la civilización, de un determinado estado (Gramsci, 1975, p.16).

Se necesita intelectuales en todos los ámbitos de una sociedad, reproduciendo las relaciones, valores y representaciones de las clases dominantes, para que ellas mantengan la hegemonía.

Este concepto gramsciano de la escuela, así como toda la teoría de distribución del poder en la sociedad, serían desarrollados décadas más tarde por el filósofo y teórico social Michel Foucault (Poitiers, 1926 - París, 1984). Este autor centró sus reflexiones en la cuestión del poder y de las instituciones sociales. Res- pecto del uso que el Estado realiza de esas instituciones, Foucault plantea que las políticas estatales tienen que ver con los necesarios pactos o acuerdos orientados a facilitar y hacer posible la tarea de gobernar $^{1}$. Se sabe que, para facilitar las tareas de gobernar y disciplinar, el Estado recurre a las instituciones educativas (escuelas, museos, salas de concierto) y regimentadoras (ejército, hospitales psiquiátricos, cárceles).

Si se recuerda que "Gobierno es la recta disposición de las cosas [territorio y personas], de las que uno se hace cargo para conducirlas a un fin conveniente" (Guillaume de La Perrière, en Foucault, 1999, p.183) resulta claro que las políticas públicas son intervenciones que persiguen un clima adecuado para poder "controlar y movilizar [a la sociedad de masas emergente, que tienen demandas políticas y males sociales] para la supervivencia nacional y el desarrollo en un orden global cada vez más competitivo"(Vaughan, 1997, p.11).

La prensa es otra institución en apariencia asentada exclusivamente en un espacio público que también cumple funciones hegemónicas. En el análisis de Gramsci se aprecia esta relación orgánica entre instituciones políticas y de la sociedad civil, que participan en la hegemonía o la contrahegemonía, según el caso. No solo se trata de que la prensa esté vinculada con la producción cultural, sino de que, en efecto, tiene a su cargo importantísimas funciones de reproducción ideológica. Por otro lado, también participa de un sector especializado del mercado: produce, distribuye y vende mercancías más o menos cotizadas y dirigidas a ciertos sectores de compradores: libros, revistas, diarios.

1 Foucault también alude a Maquiavelo: "El vínculo frágil del príncipe con su principado es lo que el arte de gobernar [...] debe tener como objetivo” (Foucault, 1999, p.187). 
En consecuencia, para Gramsci, el periodismo "no solo trata de satisfacer las necesidades - de una cierta categoría-de su público, sino que se esfuerza por crear y desarrollar estas necesidades y de estimular, en un cierto sentido, a su público y de aumentarlo progresivamente" (Gramsci, 1975, p.143). Es decir, que dos de sus funciones son reclutar y formar lectores. Añade más adelante: "Los lectores deben ser considerados desde dos puntos de vista principales: 1) como elementos ideológicos 'transformables' filosóficamente, capaces, dúctiles, maleables a la transformación; 2) como elementos 'económicos' capaces de asimilar las publicaciones y de hacerlas asimilar a los demás" (Ibid., p.144).

Aquí el autor "riza el rizo", pues los lectores participan de la economía no solo como consumidores de mercancías culturales, sino también como multiplicadores ideológicos y de clientes. Y todas estas funciones se encuentran imbricadas: "el elemento ideológico es un estímulo para el acto económico de la adquisición y de la difusión" (Gramsci, 1975, p.144). Para que no queden dudas respecto de este planteamiento, añade más adelante:

no se puede hablar de actividad periodística y editorial seria si falta este elemento, es decir: la organización del cliente, de la venta, y el hecho de que siendo el cliente un particular (en su mayor parte) necesita una organización particular ligada estrechamente al carácter ideológico de la 'mercancía vendida'. Es sabido que en un diario moderno el verdadero director es el director administrativo y no el de redacción (Gramsci, 1975, p. 145).

En estas apreciaciones, que prefiguran la complejidad y organicidad de los espacios culturales especializados, yo encuentro una anticipación de conceptos del sociólogo francés Pierre Bourdieu (Denguin, 1930 - París, 2002). Me refiero a las que tienen que ver con los procesos de conformación y especialización creciente del campo cultural y el de formación de lectores; la relación orgánica entre la formación de un público lector, el crecimiento del mercado editorial, y el desarrollo del campo literario, entre otras. Más allá de que Bourdieu no se refiera a Gramsci ni a Marx en sus textos, se fundamenta en lecturas de estos autores: todos los conceptos mencionados hablan de estructuras, es cierto, pero también muestran la relación orgánica entre las esferas -consideradas separadas por el materialismo mecanicista- de la superestructura y la base económica de las sociedades.

$\mathrm{Al}$ hablar de bloque histórico, es importante insistir en que se trata de procesos inestables, de construcciones y desplazamientos: "La hegemonía de la clase dominante sólo se alcanza cuando se ha logrado establecer esta necesaria imbricación y presuposición entre los procesos de producción material de la vida y los procesos sociales de producción espiritual" (Acanda, 2007, p.11). Estos procesos implican una comprensión relacional del poder, que no se limita a los aparatos de coerción del Estado (Ibid., p.17), sino que permea todos los procesos sociales. Es diferente de la concepción liberal de poder (cesión del mismo al Estado); el economicismo marxista no se aparta de esta noción de poder. En ambos casos, se trata de una "comprensión institucional del poder, que lo limita a la actividad de los aparatos de Estado" (Ibid., p.18).

Para Gramsci, son orgánicas las relaciones entre poder y cultura, entre política y cultura. En ello se fundamenta la teoría de la hegemonía, la cual permite 
comprender "la dimensión cultural de la política, a la vez que la dimensión política de la cultura" (Acanda, 2007, p.19). A su vez, ambas dimensiones son orgánicas a la económica, noción clave que permite comprender que "la subversión es dominación [es un] proceso que atañe no sólo a lo económico y a lo estatal, sino también a lo cultural. 'La valorización del hecho cultural es necesario junto a lo meramente económico y político"' (Ibid., p.17).

El autor revela la complejidad de las tareas necesarias para lograr la reforma moral e intelectual, que es un cambio profundo en el pensamiento, indispensable para que se consolide un bloque histórico.

Gramsci planteó el problema claramente: '¿Puede haber una reforma cultural, es decir, una elevación civil de los estratos deprimidos de la sociedad, sin una precedente reforma económica y un cambio en la posición social y en el mundo económico? Una reforma intelectual y moral no puede dejar de estar ligada a un programa de reforma económica, o mejor, el programa de reforma económica es precisamente la manera concreta de presentarse de toda reforma intelectual y moral' (Acanda, 2007, p.9).

El autor cubano plantea que:

una concepción compleja sobre la composición de la intelectualidad orgánica tiene mucho que ver con la interpretación gramsciana sobre la hegemonía. La intelectualidad es el agente social de afianzamiento de la hegemonía, pero para Gramsci la hegemonía no es un fenómeno exclusivamente ideológico (Acanda, 2007, pp. 3031).
Más aún, "resaltar el componente ético-cultural de la hegemonía no significó nunca, para Gramsci, desconocer el necesario componente económico de la misma" (Acanda, 2007, p.31).

Es cierto que la función hegemónica de una clase dominante es cumplida por el Estado, el cual, como institución, detenta el ejercicio monopólico de la violencia; pero también lo es que este "dominio directo" se cumple a través de la coerción y el consenso, con apoyo del "gobierno jurídico". Al mismo tiempo las "enormes fortalezas y casamatas" que dan apoyo a esa institución, las construye la sociedad civil, y sus ejecutores -que son a la vez productores y reproductores de bienes espirituales- son los intelectuales, en la amplia acepción del término que propone Gramsci².

Como se puede ver, hasta aquí hemos hablado de los conceptos de Estado y sociedad civil, orgánicamente relacionados y que han convocado a otros conceptos que se presuponen también en los planteamientos gramscianos: hegemonía, bloque histórico, intelectuales, reforma moral e intelectual. Finalmente, llegamos al concepto de modernización de la economía. Este se refiere a los cambios que se producen en el patrón de acumulación, orientados a patrones más avanzados, en el sentido de una mejor articulación de una economía y un país al sistema capitalista global.

En este sentido, las revoluciones pasivas son las revoluciones burguesas

2 Gramsci amplía el concepto de intelectuales. Para este autor, incluye a:

todos aquellos que desarrollan funciones organizativas en la producción, la política, la administración, la cultura, etc. No sólo los escritores y artistas, sino también los maestros de escuela, los políticos profesionales, los administradores, los técnicos, los arquitectos, etc. en tanto participan en la labor de producción, reproducción y difusiónde valores, modos de vida, modos de actividad, principios de organización del espacio, etc., son intelectuales. En tanto el poder se estructura, existe y se ejerce en todos estos intersticios de lo social, y la hegemonía de la clase dominante se enraíza en ellos, intelectuales serán los encargados del funcionamiento del aparato hegemónico, o aquellos que con su actividad contribuyen a la construcción de espacios de contrahegemonía (Acanda, 2007, pp.23-24). 
que tuvieron lugar en algunos países de Europa en el siglo XIX, en las cuales las clases subalternas fueron movilizadas, pero sin desempeñar un rol activo. Son también los cambios modernizadores tardíos en países periféricos afectados por el desarrollo desigual del capitalismo. Este desarrollo desigual hizo posible que, hasta mediados del siglo XX - para el caso de Latinoamérica- existieran Estados controlados aún por grupos o clases que no promovían el modo de acumulación capitalista. Los cambios, en estos casos, provinieron de las élites más proclives a la articulación al capitalismo. Ellas impulsaron cambios "desde arriba", sin implicar que se hubiera subvertido el orden social: se lo ha modernizado, únicamente.

Una revolución pasiva es, entonces, una modernización sin intervención activa de las clases subalternas; procesos en los que estas clases son movilizadas pero no desempeñan un rol activo. Ejemplo de ello son las revoluciones burguesas en algunos países europeos, como Alemania e Italia (il Risorgimento, en este segundo país); también lo son los procesos impulsados por Lázaro Cárdenas, en el México de la década de 1930, y en el Brasil de Getulio Vargas, en la de 1940.

Il Risorgimento es el proceso de unificación de Italia en el siglo XIX. Según Gramsci, este proceso fue un cambio que no consiguió ser revolucionario porque las élites no incorporaron a las masas subalternas cuyo grueso era el campesinado, en particular el de las empobrecidas regiones de Italia meridional. La falta del apoyo de este grupo social, como había ocurrido en Francia, marcó la diferencia, y la aristocracia no consiguió ser derrotada. En el análisis de este proceso es que Gramsci desarrolla nociones importantes como la de hegemonía, sociedad civil y revolución pasiva, entre otras. Se pregunta:

El concepto de 'revolución pasiva', en el sentido que Vicente Cuoco atribuye al primer período del Risorgimento italiano, ¿puede ser correlacionado con el concepto de 'guerra de posición' confrontado con el de guerra de maniobras? Estos dos conceptos se formaron después de la Revolución Francesa y el binomio Proudhon-Gioberti ¿pueden ser justificados por el terror creado en 1793, como el sorelianismo, por el pánico que siguió a los estragos parisienses de 1871? Entonces, ¿existe una identidad absoluta entre guerra de posición y revolución pasiva? O, por lo menos, ¿existe o puede concebirse todo un período histórico en el que los dos conceptos puedan identificarse hasta el punto que la guerra de posición se transforme en guerra de maniobras? Es un juicio 'dinámico el que es necesario dar sobre las 'restauraciones', las que serían una 'astucia de la providencia' en el sentido que le dio Vico (Gramsci, 2008, p. 167).

Y Gramsci prosigue su análisis. Más allá de que el Partido de la Acción (el de Mazini y Garibaldi) hubiera sido progresista, finalmente, bajo la guía de los moderados, resultaron derrotados por los cavourianos. El éxito de estos últimos radicó en la relación orgánica entre dirigentes políticos, intelectuales, terratenientes y dirigentes industriales. Los industriales del norte, en alianza con los terratenientes del Meridiano, mantuvieron a los campesinos y a los obreros en un rol pasivo (mientras los católicos, por ejemplo, nunca dejaron de tener una participación activa, "con hombres propios, con partido propio, con programa propio") (Gramsci, 2008, p.176).

Es de hacer notar que el mismo partido tradicional de la Constituyente en Italia, el Republicano, demostró el mínimo de sensibilidad histórica y de capacidad política y se dejó imponer el programa y la di- 
rección (o sea una defensa abstracta y retrospectiva de la participación en la guerra) de grupos de la derecha. El pueblo, a su modo, miraba al futuro (también en la cuestión de la intervención en la guerra) y en eso estriba el carácter implícito de constituyente que el pueblo dio a las elecciones de 1919; los partidos miraban al pasado (solo al pasado) concretamente y al porvenir 'abstractamente', 'genéricamente', como 'tened fe en vuestro partido', y no como concepción histórico política constructiva." (Gramsci, 2008, p. 176).

Por otro lado, para Gramsci es una cuestión importante pensar que no son suficientes los procesos modernizadores, más allá de que éstos puedan implicar en ámbitos específicos-instancias liberadoras. Para el pensador italiano, se debe apuntar a la conformación de un nuevo bloque histórico en el que las clases subalternas no estén enajenadas de los medios de producción. Para ello, es requisito fundamental -y a ello vuelve Gramsci, una y otra vez-, la reforma moral e intelectual:

La importancia del consenso activo, y por ende de la conformación de un sustrato cultural que permita la independencia intelectual de cada individuo, confirma la idea gramsciana del papel esencial a jugar por la sociedad civil en la estructuración de la nueva hegemonía. La revolución socia- lista es el inicio de una larga etapa cuya finalidad consiste en la desaparición de la sociedad política y el advenimiento de lo que Gramsci denomina 'sociedad regulada'. El derrocamiento del Estado capitalista no tiene como objetivo su sustitución por otra forma de Estado, sino la erección de "una sociedad capaz de autodirección y que por ello no necesita más un Estado político" (Acanda, 2007, p. 44).

Para Gramsci, los procesos modernizadores merecen la crítica por cuanto no buscan desarrollar en los subordinados las herramientas del "buen sentido", sino que los mantiene en un rol pasivo y alienante, muy lejos de la necesaria reforma moral e intelectual.

Para concluir, este artículo, la reflexión en torno a estos tres conceptos $-\mathrm{y}$ su puesta en práctica en el juicio crítico a la historia italiana de la unificación-, permite realizar un recorrido por la perspectiva analítica y epistemológica de Antonio Gramsci, una de las más trascendentes reflexiones sobre el poder. El militante italiano aporta con lucidez, desde la fuerza y la autoridad que le brinda su praxis, y proporciona una caja de herramientas teóricas de las más importantes que se hayan producido entre los intelectuales del siglo XX.

\section{Bibliografía}

Acanda, J. L. (2007). Traducir a Gramsci: La Habana: s/e.

Foucault, M. (1999). "La gubernamentalidad". En Obras esenciales. Estética, ética y hermenéutica. Vol. 3. pp. 177-197. Barcelona: Paidós.

Gramsci, A. (1975). Cuadernos de la cárcel: Los intelectuales y la organización de la cultura. México: Juan Pablos Editor, S. A. (1998). Para la reforma moral e intelectual. Madrid: Los libros de la catarata. (2007). Antología. Madrid: Siglo XXI Editores. (2008). Il Risorgimento. Buenos Aires: Las Cuarenta.

Vaughan, M. K. (1997). Cultural Politics in Revolution. Teachers, Peasants, and Schools in Mexico, 1930-1940. Tucson: The University of Arizona Press. 